\title{
Quantifying Pharmacoeconomics
}

\author{
Sunil Chaudhry \\ Honorary Medical Director, Bioclinitech Technologies Pvt. Ltd, Mumbai \& GPATTutor.com, India
}

\section{*Corresponding Author: Sunil Chaudhry}

Email: sunil.r.chaudhry@gmail.com

\begin{abstract}
Healthcare expenditure is becoming a significant challenge for the financial sustainability of national health systems even in high economies. HEOR (Health Economic Outcome Research) analytics plays an increasingly vital role in a drug's approval and reimbursement with payers. In broad terms, health economists study the functioning of healthcare systems and healthaffecting behaviors such as smoking, diabetes, and obesity.
\end{abstract}

Keywords: Cost Effective Analysis, Cost Benefit Analysis, Cost Minimization Analysis, health economics, precision medicine.

\section{Introduction}

Health economics is basically defined as the science dealing with the assessment of costs and benefits. It does not make decisions about use of resources instead inform them. The objective is to recognize what is more efficient, so that largest amount of benefit can be obtained for a given sum of money. ${ }^{1}$

Pharmacoeconomics was used on a public forum for the first time in 1986 by Townsed, Pharmacoeconomics can be defined as the branch of economics that uses cost-benefit, cost-effectiveness, cost minimization, cost-of-illness and cost-utility analyses to compare pharmaceutical products and treatment strategies. Pharmacoeconomics and health outcomes research are playing an increasingly important role in informing clinical development and market access decisions of new innovative medicines. ${ }^{2}$ Fig. 1

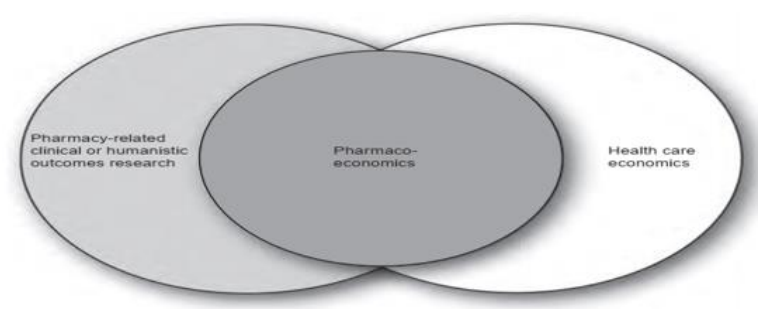

Fig. 1

Pharmacoeconomics developed its roots in 1970s. The first book on health economics was published in 1973 and in 1978; McGhan, Rowland, and Bootman from the
University of Minnesota introduced the concept of costbenefit and cost effectiveness analysis. Utilizing sophisticated pharmacokinetic protocols, Bootman published an early pharmacy research article in 1979 in which cost-benefit analysis was employed to appraise the outcomes of individualizing aminoglycoside dosages to severely burned patients with gram-negative septicaemia. In 1983, Ohio State University College of Pharmacy initiated a specialized pharmacy academic program with the objective of providing an overview of the application of cost benefit and cost effective analysis in healthcare, with emphasis on their application to the delivery of pharmaceutical care. ${ }^{3}$

The Global health care market has rising healthcare budgets which produce stress on Government and as well on Private healthcare systems. Tighter evidentiary requirements for clinical and cost effectiveness

In 1993, Australia became the first nation to use pharmacoeconomic analysis as part of the process for deciding whether new drugs should be subsidized by the Federal Government. The Pharmaceutical Benefits Advisory Committee (PBAC) advises Federal Government ministers on whether new drugs should be placed on a list for of drugs that consumers can then purchase from pharmacies at a subsidized price. Since 1993, this approach to evaluating costs and benefits is used in Canada, Finland, New Zealand, Norway, Sweden, and the UK. ${ }^{4}$ Pharmacoeconomics has become more important over the past 20 years, due to an 
increases emphasis on efficient drug therapies for disease, which increase health cost etc.

Importance of Pharmacoeconomics or Health Economic Outcome Research (HEOR) ${ }^{5}$

1. Pricing of a new drug.

2. Repricing of an old drug.

3. Convincing a drug formulatory.

4. Generation of data for promotional material.

5. Mandatory legislative requirement for drug licensing and medical reimbursement (in some countries).

Cost Parameters, Fig. 2: ${ }^{6}$

Direct Cost: This is the cost that is directly involved with the treatment like the cost of medicine, medical supplies, diagnostic tests, etc. The charges of the bed in the hospital is also included in this type.

Direct Nonmedical Cost: The cost of transportation to and fro the health center, special diets, visits to the emergency department, extra hospital visits are included in this type of costs.

Intangible cost: The pain, suffering, grief of the patients and caregivers is included in this type. This type of costs is usually excluded while forming the insurance policies

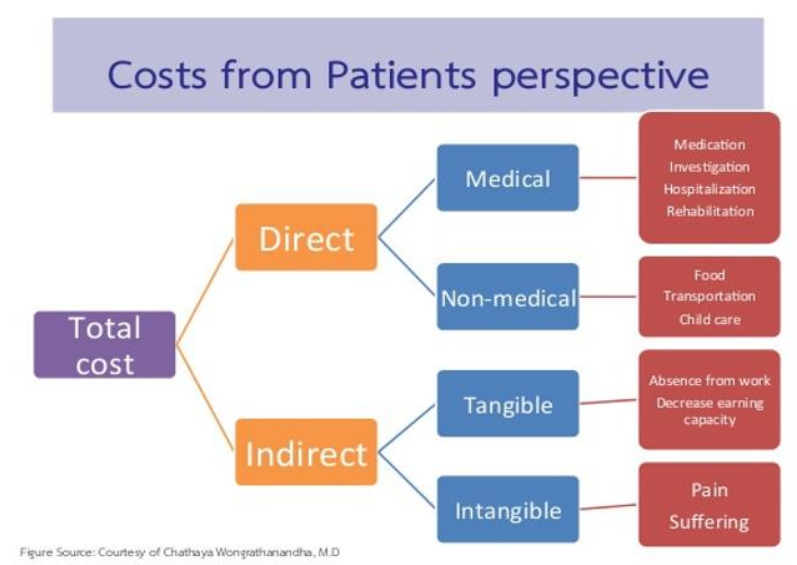

Fig. 2

Health spending can be very dramatic across countries with an income reduction, unemployment, and epidemics of chronic illness. Cardiovascular disease is the number one cause of death and in 2009, the EU estimated the costs of cardiovascular disease to be nearly 196 billion per year, which implies the necessity of financial measures to be taken by governments. ${ }^{7}$

\section{Pharmacoeconomic Analysis: ${ }^{8}$}

If therapy is not clinically effective, it is not cost effective. The impact of drug therapy on all patients should be incorporated into pharmacoeconomic study irrespective whether they are responders or non responders or patients experiencing Adverse drug reactions. The partial analyses are cost of illness and cost consequence. The full analyses are cost effective (CEA), cost benefit (CBA), cost utility (CUA) and cost minimization analysis (CMA).

\section{Cost Analysis [Table1]}

Table 1: Frequently Used Pharmacoeconomic terms

\begin{tabular}{|l|l|}
\hline $\begin{array}{l}\text { Cost- } \\
\text { Effectiveness }\end{array}$ & $\begin{array}{l}\text { Comparison that balances a single unit of cost } \\
\text { against a single unit of risk or benefits to the } \\
\text { quality of life extended to the patient. }\end{array}$ \\
\hline $\begin{array}{l}\text { Cost } \\
\text { minimization }\end{array}$ & $\begin{array}{l}\text { Comparison of multiple drugs of equal } \\
\text { efficacy and equal tolerability to identify the } \\
\text { least expensive therapy. }\end{array}$ \\
\hline Cost -utility & $\begin{array}{l}\text { Ratio between the cost of a health -related } \\
\text { intervention and benefit produces in terms of } \\
\text { number of years lived in full health. }\end{array}$ \\
\hline Cost-benefit & $\begin{array}{l}\text { Determines whether an intervention or policy } \\
\text { decision is sound (justification / feasibility } \\
\text { and provides a basis for evaluating policies by } \\
\text { comparing the total expected cost of each } \\
\text { option against the total expected benefits to } \\
\text { see whether the benefits outweigh the costs, } \\
\text { and by how much, vaccinations programmes } \\
\text { are a classic example }\end{array}$ \\
\hline
\end{tabular}

\section{Cost effectiveness analysis (CEA)}

Cost-effectiveness analysis is a way to examine both the costs and health outcomes of one or more interventions. It compares an intervention to another intervention (or the status quo) by estimating how much it costs to gain a unit of a health outcome, like a life year gained or a death prevented.

Cost-effectiveness analysis compares the costs and health effects of an intervention to assess the extent to which it can be regarded as providing value for money. This informs decision-makers who have to determine where to allocate limited healthcare resources. ${ }^{8}$ 
Table 2: Cost-Effective Analysis Matrix

\begin{tabular}{|c|c|c|c|c|}
\hline Intervention & $\begin{array}{c}\text { Cost in } \\
\text { INR }\end{array}$ & $\begin{array}{c}\text { Outcome } \\
\text { (unit) }\end{array}$ & $\begin{array}{c}\text { Cost/ } \\
\text { unit } \\
\text { outcome }\end{array}$ & $\begin{array}{c}\text { The most } \\
\text { cost } \\
\text { effective } \\
\text { therapy }\end{array}$ \\
\hline A & 100,000 & 10 & 10,000 & \\
\hline B & 100,000 & 100 & 1,000 & \\
\hline C & 100,000 & 1000 & 100 & $\begin{array}{c}\text { Most } \\
\text { optimal } \\
\text { model }\end{array}$ \\
\hline
\end{tabular}

The mean total cost using IVIG therapy was significantly less than that of CIST (Cost of Intravenous Immunoglobulin Therapy) during the entire course of the disease $(\mathrm{p}<0.001)$ and on an annual basis $(\mathrm{p}<$ $0.05)$. IVIG therapy is a safe, clinically beneficial, and less-expensive alternative treatment in patients with progressive MMP (mucous membrane pemphigoid) that is nonresponsive to conventional immunosuppressive therapy CIST. ${ }^{9}$

Table 3

\begin{tabular}{|c|c|c|c|}
\hline Programme & $\begin{array}{c}\text { Cost in } \\
\text { INR }\end{array}$ & $\begin{array}{c}\text { Health effect } \\
\text { ( Life Years } \\
\text { gained) }\end{array}$ & $\begin{array}{c}\text { Cost effectiveness } \\
\text { ratio C/E (INR/ } \\
\text { Life years gained ) }\end{array}$ \\
\hline $\mathrm{A}$ & 150,000 & 1850 & 81.081 \\
\hline $\mathrm{B}$ & 100,000 & 1200 & 83.333 \\
\hline $\mathrm{C}$ & 120,000 & 1350 & 88.888 \\
\hline
\end{tabular}

\section{Cost minimization analysis (CMA)}

This involves measuring only costs, usually only to the health service, and is applicable only where the outcomes are identical and need not be considered separately. An example would be prescribing a generic preparation instead of the brand leader. Generic medicines are gaining momentum as they are effective and can save considerable costs. Such shops are now operating for patient benefit.

Generic medications typically cost about $80 \%$ to $85 \%$ less than the same brand-name drug. According to 1 study, generic drugs saved the U.S. healthcare system \$1.67 trillion from 2007 to 2016

Generic medications are just as effective as brandname drugs. According to the FDA, drug makers must prove that generic medications can be substituted for brand-name drugs and offer the same benefits as their brand-name counterparts.

Reasons for brands to be expensive

The manufacturers of brand-name medications have to conduct tests, known as clinical trials, to prove that their drug is safe and works the way it's supposed to. These tests are expensive, and manufacturers pass on some of these costs to the consumer.

Brand-name drug is only sold by one manufacturer, several companies will usually sell the same generic drug, which leads to competition in the marketplace and lower costs for consumers.

Table 4: The example is shown in below.

\begin{tabular}{|c|c|c|c|c|c|c|}
\hline $\begin{array}{l}\text { Sr. } \\
\text { No. }\end{array}$ & Brand Name & Manufacturer & $\begin{array}{c}\text { Number of } \\
\text { drugs per } \\
\text { strip }\end{array}$ & Content & $\begin{array}{c}\text { Price per } \\
\text { strip } \\
\left(\text { INR }^{*}\right)\end{array}$ & $\begin{array}{c}\text { Price Per } \\
\text { Tab. } \\
\text { (INR*) }\end{array}$ \\
\hline 1 & Januvia & MSD & 7 & Sitagliptin 50 mg & 269 & 38.42 \\
\hline 2 & Zeta & Glenmark & 7 & Sitagliptin $50 \mathrm{mg}$ & 98 & 14 \\
\hline 3 & Glycomet & US Vitamins Limited & 10 & Metformin $500 \mathrm{mg}$ & 16.95 & 1.69 \\
\hline 4 & Glyciphage & $\begin{array}{l}\text { Franco Indian } \\
\text { Remedies }\end{array}$ & 20 & Metformin $500 \mathrm{mg}$ & 29.20 & 1.46 \\
\hline 5 & Forson & Unison & 10 & Metformin $500 \mathrm{mg}$ & 8.7 & 0.87 \\
\hline
\end{tabular}

Biosimilars of various therapeutic areas are much economical as compared to Innovators. Due to health burden, Regulatory authorities approve use of Biosimilars for large population, even in Europe.

\section{Advantages}

1. It facilitates selection of cheaper drugs

2. It is the simplest of the four types of pharmacoeconomics analysis because the focus is on measuring the left hand side (cost) of the pharmacoeconomics equation. It is very useful in evaluating the cost of a specific drug

3. Because it compares the cost of two alternatives, it helps identify the cheapest method/drug to use hence maximized profits/benefits.

4. It is most useful for comparing generic and therapeutic equivalents or «me too» drugs

\section{Disadvantages}

1. It can only be used to compare two products that have been shown to be equivalent in dose and therapeutic effect.

2. In many cases, there is no reliable equivalence between two products and if therapeutic equivalence cannot be demonstrated, then costminimization analysis is inappropriate (WHO, 2003). ${ }^{10}$

\section{Cost of Illness Evaluation (COI), [Table 5]}

It is also referred to as burden of illness. COIs are important in Pharmacoeconomic evaluations of new 
drug therapies. It identifies and estimates the overall cost of a particular disease for a defined population, COI evaluation is not used to compare competing treatment alternatives.

Eg.: Alzheimer's disease. ${ }^{11}$ The COI studies traditionally stratify costs into three categories direct, indirect, and intangible costs. Since the intangible costs have been quantified in COI studies due to the measurement difficulties and related controversies, here we mainly focus on the first two cost categories. The examples of direct and indirect costs associated with health outcomes.

\section{Table 5:}

\begin{tabular}{|l|l|l|}
\hline $\begin{array}{l}\text { Direct Health Care } \\
\text { Costs }\end{array}$ & $\begin{array}{l}\text { Direct Non } \\
\text { Health Care } \\
\text { Costs }\end{array}$ & Indirect Costs \\
\hline Institutional care & Legal cost & $\begin{array}{l}\text { Productivity } \\
\text { losses }\end{array}$ \\
\hline Physician services & $\begin{array}{l}\text { Transportation } \\
\text { cost }\end{array}$ & Absenteeism \\
\hline Nurses, Physiotherapists & Counselling cost & $\begin{array}{l}\text { Visitors and } \\
\text { family } \\
\text { attending } \\
\text { patients }\end{array}$ \\
\hline $\begin{array}{l}\text { Drug Costs / } \\
\text { Surgery/Vaccination products } \\
\text { Blood } \\
\text { /Radiation Therapy }\end{array}$ & $\begin{array}{l}\text { Programme } \\
\text { evaluation }\end{array}$ \\
\hline Ambulance & & \\
\hline Training and Education & & \\
\hline
\end{tabular}

Table 6: Cost utility Analysis (Outcome measures).

\begin{tabular}{|l|l|}
\hline $\begin{array}{l}\text { QALY -Quality- } \\
\text { adjusted Life Year } \\
\text { Measurement }\end{array}$ & $\begin{array}{l}\text { Is generic measure of disease burden, } \\
\text { including both the quality and the quantity } \\
\text { of life lived. It is used in economic } \\
\text { evaluation to assess the value of medical } \\
\text { interventions. }\end{array}$ \\
\hline $\begin{array}{l}\text { Quality of well } \\
\text { being }\end{array}$ & $\begin{array}{l}\text { Health quality of life questionnaire which } \\
\text { measures overall status and well-being } \\
\text { over the previous three days in four areas: } \\
\text { physical activities, social activities, } \\
\text { mobility, and symptom/problem } \\
\text { complexes. It consists of 71 items and } \\
\text { takes 20 minutes to complete. }\end{array}$ \\
\hline $\begin{array}{l}\text { Health Utility } \\
\text { Index }\end{array}$ & $\begin{array}{l}\text { The Health Utilities Index (HUI) is a } \\
\text { rating scale used to measure general } \\
\text { health status and health-related quality of } \\
\text { life (HRQoL). }\end{array}$ \\
\hline Cost Utility Index & $\begin{array}{l}\text { Economic analysis in which the } \\
\text { incremental cost of a program from a } \\
\text { particular point of view is compared to the } \\
\text { incremental health improvement } \\
\text { expressed in the unit of quality adjusted } \\
\text { life years (QALYs) }\end{array}$ \\
\hline
\end{tabular}

Cost-utility analysis incorporates changes in the quantity of life (mortality) and changes in the quality of life (morbidity) into a single 'unit of health' metric. The concept of health adjusted life years (HALYs) has been developed by health economists, and the two most common metrics of this type are the quality adjusted life year (QALY, broadly useful as a measure of health gain from interventions) and the disability adjusted life year (DALY). The DALY is a measure of the gap between an existing health state and a hypothetical ideal, and thus is a metric suited to burden of disease. The fundamental calculation for DALYs is:

\section{DALY $=$ YLL+YLD}

YLL is the number of years of life lost due to mortality and YLD is the number of years lived with a disability, weighted with a factor between 0 and 1 for the severity of the disability. ${ }^{5}$ Anticoagulation with Warfarin for prevention of ischemic stroke appeared to be cost-saving relative to the costs of stroke.

Inference: Cost data vary from country to country, reflecting differences in resources use patterns and relative unit cost levels. An example of this is the variation in length of stay for surgical procedures that vary from place to place. Preferences for health states often depend on cultural factors that vary among countries

Empiric IVIG therapy is a cost-effective strategy for the treatment of women at risk for foetal and neonatal alloimmune thrombocytopenia when the rate of perinatal ICH (intra cerebral haemorrhage) is less than $28 \% .^{11}$

Pharmacoeconomics can be applied to retrospective and prospective studies involving the drug. Pharmacoeconomic evaluations and clinical trials can be conducted in conjunction with each other in several ways:

1. A clinical trial can be designed to test the safety and efficacy of a drug, followed by a pharmacoeconomic evaluation.

2. A clinical trial can be designed to conduct a pharmacoeconomic evaluation.

3. Clinical data collected prospectively in a clinical trial can be used to conduct a retrospective or prospective pharmacoeconomic evaluation. ${ }^{12}$ 
Cost Benefit Analysis (CBA), Table 3 (Benefit /Cost) CBA is a fundamental tool to improve the decision making process in deciding the funds to healthcare programs. Therefore, assessment can be made on whether the total costs of an intervention are justified by its total benefits. Cost Benefit Analysis mainly involves identification, measurement, comparison of the benefits and costs of the program or treatment alternatives.

a. Developing benchmarks for comparing projects

b. Deciding whether to pursue a proposed project

c. Weighing investment opportunities

The net benefits measure derives one figure for each regulatory alternative. The net benefits measure is the difference between the monetized costs and monetized benefits of a regulatory alternative. The net benefits measured is expressed in any currency.

Table 7: Cost Benefit Analysis Example

\begin{tabular}{|c|c|c|c|}
\hline & $\begin{array}{c}\text { Solution } \\
\text { A }\end{array}$ & $\begin{array}{c}\text { Solution } \\
\text { B }\end{array}$ & $\begin{array}{c}\text { Solution } \\
\text { C }\end{array}$ \\
\hline Total Cost in INR & 100,000 & 150,000 & 200,000 \\
\hline Total Benefits & 120,000 & 190,000 & 230.000 \\
\hline Cost Benefit Ratio & 1.20 & 1.266 & 1.15 \\
\hline
\end{tabular}

The benefit-cost ratio formula is the discounted value of the project's benefits divided by the discounted value of the project's costs If a project has a BCR greater than 1.0 , the project is expected to deliver a positive net present value to a firm and its investors. If a project's BCR is less than 1.0, the project's costs outweigh the benefits, and it should not be considered.

One of the analysis indicated that Ibandronate was associated with a lower fracture-care cost per patient compared with Alendronate and Risedronate. A Markov model by Parthan et al. comparing oral bisphosphonates with denosumab in the U.S. PMO population found that, overall, denosumab dominated branded risedronate. In several analyses of high-risk subgroups among women 75 years of age and older, denosumab outperformed all oral bisphosphonates, in terms of efficacy and cost. ${ }^{13}$

The reports of economic evaluations should be clear and detailed, and the analysis should be presented in a transparent manner. The report should provide enough information to enable the audience to critically evaluate the validity of the analysis. The report format should be well structured and easy to follow.

\section{Big Data and Predictive Analytics}

Big data in healthcare refers to huge health-related data sets and their associated predictive analytics. Common uses for big data include: providing population characteristics; identifying risk factors and developing prediction (diagnostic or prognostic) models; observational studies comparing different interventions; exploring variation among healthcare providers; and as a supplementary source of data for another study. The main advantages of big data analyses are their comprehensive nature, the immense populations they can accommodate, and the ability to compare healthcare providers. The main challenges are demonstrating data quality, the difficulty in applying a causal interpretation to the study findings, and a nonwillingness by stakeholders such as healthcare providers to accept new methods. Currently, big data is most closely associated with electronic medical record databases and claims-based databases. ${ }^{14}$

Market access: Often confused with health economics, market access is a distinctly separate area, although it does work in conjunction with HEOR. The definition of market access is ensuring that patients are able to access drugs quickly and continuously, and marketed at reasonable price that is line with the drug's effectiveness in treating disease. While their goals may be aligned, market access is far more concerned with product pricing and the success of a drug than health economics. $^{15}$

The main challenges for pharmacoeconomics continue to be:

a. Establishing guidelines or standards of practice.

b. Creating a cadre of trained producers and consumers of pharmacoeconomic work.

c. Continuing education on the relevant features of this discipline for practitioners, government officials, private sector executives.

d. Stable funding to support applied pharmacoeconomic research.

Budget impact model/analysis (BIA): These assess how affordable a product is within the current market compared with products already on the market. This 
includes comparing expense to efficacy. Are there less expensive drugs on the market that are just as effective, or more so? It also helps to predict whether the drug will be bought by major stake holders like the NHS. (National Health Service)

\section{Cost Sharing Approach}

Cost sharing is a commonly used approach to control access and expenditure even though it disproportionately affects low-income individuals. A form of splitting the cost of healthcare services in order to reduce public expenditure on the service, it aims to generate income or reduce expenditure for the thirdparty payer, to reduce administrative costs, to make users cost-conscious, to promote competition, to reduce abuse and inefficiency and to facilitate access where needed. Countries where this approach is used include Austria, Italy, UK, Belgium, France, Greece, Estonia, Finland, Latvia, Lithuania, Poland, Portugal, Slovakia, Slovenia, Spain, Cyprus, Germany, Norway, Denmark, Sweden and Ireland. ${ }^{16,17}$

\section{Conclusions}

The pharmacoeconomic analyses are very useful in effective formulary management which most countries are adopting. It is also helpful in individual patient treatment. In many countries, medication policy mandates HEOR which is very essential for proper health care management and resource allocation.

Health economics represents a valuable tool for improving the information base upon which healthcare decisions are made. It can help to inform and improve decision-making, as a systematic and objective system of thought.

Applied pharmacoeconomics is alternative term for HEOR putting pharmacoeconomic principles, methods, and theories into practice to quantify the value of pharmacy products and pharmaceutical care services used in real-world environments.

\section{Source of Funding}

None.

\section{Conflict of Interest}

None.

\section{References}

1. Javangula $\mathrm{H}$, An overview of pharmacoeconomics and outcome research. Int J LifeSc Bt Pharm Res 2012.

2. Kumar S, Baldi A, Pharmacoeconomics: Principles. Method Econ Eval Drug Ther 2013;2(5).

3. Scaria S, Raju R, Joseph S, Mohan A, Nair AA, Pharmacoeconomics: Principles, Methods and Indian Scenario. Int J Pharm Sci Rev Res 2015;34(1):37-46

4. https://en.wikipedia.org/wiki/Pharmacoeconomic

5. Gattani S, Patil A, Kushare S. Asian J Pharm Clin Res. 2009;2(3).

6. Anders B, Ommen O, Direct, indirect, and intangible costs after severe trauma up to occupational reintegration - An empirical analysis of 113 seriously injured patients. GMS Psycho-Soc-Med 2013;10:2.

7. Stepovic M, GDP Growth and Health Care Expenditures Worldwide. Open Pharmacoecon Health Econ J 2019;7.

8. Rai M, Goyal R, In Pharmaceutical Medicine and Translational Clinical Research, 2018

9. Doud Y, Cost of Intravenous Immunoglobulin Therapy Versus Conventional Immunosuppressive Therapy in Patients with Mucous Membrane Pemphigoid: A Preliminary Study. Ann Pharmacother 39(12):2003-8

10. Jainam $S$, Pharmacoeconomic evaluation of antidiabetics. Inter J Med Res and Health Ser 2016;5(3):34-43.

11. Changik Jo, Cost of illness studies. Clin Mol Hepatol 2014;20.

12. The Cost Effectiveness of Empiric Intravenous Immunoglobulin for the Antepartum Treatment of Fetal and Neonatal Alloimmune Thrombocytopenia. Am J Obstet Gynecol 2005;193(3 Pt 2):1094-9.

13. Ahmad A, Patel I, Parimilakrishnan S, Mohanta GP, Chung HC, Chang J. The role of pharmacoeconomics in current Indian healthcare system. J Res Pharm Pract 2013;2(1):3-9.

14. Kristie NT, Lie JD, Wan CKV, Cameron M, Austel AG, Nguyen JK et al, Osteoporosis: A Review of Treatment Options. Pharm Ther 2018;43(2):92-104.

15. Chen Y, Guzauskas GF, Gu C, Wang BCM, Furnback WE, Xie $\mathrm{G}$ et al, Precision Health Economics and Outcomes Research to Support Precision Medicine: Big Data Meets Patient Heterogeneity on the Road to Value. J Pers Med 2016;6:20

16. Kumar A, Kiskore P, Pharmaceutical market access in emerging markets: concepts, components, and future. $J$ Mark Acc Health Policy 2014;2:25302

17. Maniadakis N, Market Access in European Union Countries. Health Manag 2008;2(2).

How to cite: Chaudhry S. Practicing health economic outcome research or pharmacoeconomics. J Pharm Biolog Sci 2020;8(1):32-7. 